\title{
BOUNDARIES AND BELONGING IN THE INDO-MYANMAR BORDERLANDS: CHIN REFUGEES IN MIZORAM ${ }^{1}$
}

\section{Kirsten McConnachie, University of Warwick}

\begin{abstract}
This article examines the reception of Chin refugees from Myanmar in Mizoram State in northeast India through the framework of boundaries and belonging. Strong historical, cultural and ethnic connections between Chin and Mizo might suggest a strong claim to belonging. This has been true to some extent but the reception of Chin in Mizoram has also been shaped by perceived otherness. This article explores the co-existing discourses of Chin as other/brother in relation to processes of boundary-making, boundary-policing and boundary-manipulation. It argues that these contrasting narratives illustrate a dynamic relationship between national borders and boundaries of belonging which speak to deeper truths about the legitimacy of the nation-state and the role of place, politics and identity in the construction of insiders and others. This case study generates several conclusions of wider relevance to refugee studies, namely the flexibility of perceptions of belonging, the possibility of deliberately reshaping perceptions of belonging, and the existence of multiple, overlapping identities (i.e. citizenship, faith, ethnicity and culture) which are accorded different weight and value at different times.
\end{abstract}

\section{Introduction}

Refugee reception is often analysed as primarily determined by national and international law and policy. However, laws and policies are enacted in societies and can be reinforced or undermined by local realities. For example, national policies of rejection can be subverted by local generosity, while a national policy of tolerance towards refugees can be undermined by local hostility and discrimination. ${ }^{2}$ Of course, the range of local responses is not restricted to hospitality or hostility. Refugees are quintessential outsiders in a society whose non-belonging is inherent in their refugee status and lack of citizenship, but their survival also depends on

\footnotetext{
${ }^{1}$ This article was presented at the workshop on InterAsian Connections at Seoul National University in April 2016 and the University of Oxford's Asia Studies Centre public seminar series in April 2017. I am grateful to the participants at both events, to Elaine Ho and Cabeiri Robinson for editorial support, to the anonymous reviewers for their detailed suggestions, and to Naomi Creutzfeldt for commenting on multiple drafts. I would also like to thank everyone who participated in the research and facilitated my time in Aizawl and Mizoram. This research was funded by the John Fell Fund and by Ockenden International during my tenure as the Joyce Pearce Junior Research Fellow in Refugee Studies at the University of Oxford (2012-2015).

${ }^{2}$ An example of the former is the Acehnese fishermen who rescued Rohingya refugees refused entry by the governments of Thailand, Malaysia and Indonesia (see McNevin, this issue).
} 
putting down roots: securing a place to live and work, learning to communicate in a foreign language. Thus, belonging is a negotiated condition forged between refugees and their host communities. The nature of this process is an important window into the lived conditions of forced migrants, in terms of who is permitted to belong, what belonging looks like and how it can be achieved or promoted. It also has important implications for refugee law and policy, in (for example) understanding how and why local reception varies for different refugee populations. This is relevant to every aspect of refugees' lives, though is perhaps particularly salient for durable solutions planning, as local acceptance of refugees' claim to belonging is central to the success of resettlement, repatriation and local integration.

Belonging has been a central research question in migration studies for some time, along with related topics such as integration, assimilation and multiculturalism (Castles and Davidson 2000, Yuval-Davis 2006, Delanty et al 2008). It has been less prominent in refugee studies, only emerging as a core research theme relatively recently (Hovil 2016, Brun et al 2017). One reason for this may be that refugee studies has by definition approached refugee status as a privileged analytical category and in doing has arguably neglected to recognise refugees as possessing multiple identities and communities of belonging, related to (e.g.) faith, culture, religion, language, gender and others. As will be argued below, these identities are often more influential in shaping local reception and boundaries of belonging than the universal category of "refugee".

This article recognises belonging as an interaction between place, politics and identity and draws on borderland studies, identity studies and refugee studies to examine the significance of "boundaries and belonging" for Chin refugees in the northeast Indian state of Mizoram. Boundaries have been a central concept in identity studies for several decades, as an approach that recognises community as relational, evolving and constructed by cognitive distinctions between 'insiders' and 'outsiders'. In Barth's famous phrase (1969:15), “the critical focus of investigation from this point of view becomes the ethnic boundary that defines the group, not the cultural stuff that it encloses." The boundaries constructing identity are not only cognitive but can also be territorial. Mizoram has two international borders (with Myanmar to the east and Bangladesh to the south) and three borders with other northeast Indian States (Assam, Manipur and Tripura). As with many borderlands, Mizoram is simultaneously a space of international connection and of highly localised differentiation of identities and entitlements. This article focuses on Mizoram's border with Myanmar, and therefore with Chin State. 
Mizoram and Chin State are small and ethnically distinct sub-states which have considerably more in common with each other than with their respective 'parent' nations of India and Myanmar. Strong historical, cultural and ethnic connections between Chin and Mizo might suggest that those arriving would easily integrate into Mizoram. This has been true to some extent but reception of Chin in Mizoram has also been shaped by their perceived otherness. They have been resented, rejected and blamed for a host of social problems, including the production and sale of alcohol and drugs. On several occasions low-level resentment has escalated to mass pushbacks across the border to Myanmar. Alongside these processes of othering is a parallel discourse that recognises the Chin as co-ethnics and kin, a discourse that in Mizoram is often framed around pan-ethnic identity, typically Zo. This discourse exists as a counterpoint to prejudice and scapegoating and has arguably afforded the Chin a unique status in Mizoram, as outsiders who simultaneously have a claim to belonging.

The relationship between Mizo-Chin has not evolved in a neat trajectory - reality rarely does - but this case study provides a number of valuable insights nevertheless. Responses to Chin in Mizoram illustrate a dynamic relationship between national borders and boundaries of belonging, and the changing contours of this relationship speak to deeper truths about the legitimacy of the nation-state and the role of place, politics and identity in the construction of insiders and others (Migdal 2004; Van Houtum and Van Naerssen 2002). The analysis presented here also reinforces central insights on the nature of boundaries and belonging, including that belonging is flexible (and therefore malleable), identities are multiple (and therefore accorded different weight and value at different times), and that the boundaries of both are constantly under negotiation.

\section{Methodology}

This article is drawn from fieldwork conducted in Mizoram during July 2014 and June, July and August 2015. I conducted semi-structured and unstructured interviews with 125 people in Aizawl and in southern Mizoram (Lai Autonomous District and Mara Autonomous District). Related fieldwork was conducted in New Delhi and Kuala Lumpur between 2013 and 2015, and in Chin State in December 2014. Interviews were recorded with the consent of the participant, or written notes were taken when this was the preference of the interviewee. All interviews were conducted in English or with the assistance of an interpreter. I used a number of interpreters to access different communities. 
Research with refugee populations is often sensitive and this is certainly the case in Mizoram. As a white, Western, female researcher, I was unmistakably an outsider and was treated with great hospitality - and some suspicion. My research topic and ability to be objective was repeatedly challenged: "What do you want to do in Mizoram? And do you think that you will get the truth? Do you think that people will tell you honestly, on both sides?"3 As with any other qualitative research project, I have tried to "get the truth" by seeking out and weighing up as many sources of information as possible. My multi-sited fieldwork had advantages in triangulating information, as many refugees in New Delhi and Kuala Lumpur had lived in Mizoram at some point or have friends and family who had done so. I could discuss conditions in Mizoram with people who were not invested in that context and perhaps were more able to speak freely. Equally, I was able to build trust with interviewees in Mizoram by discussing conditions in Kuala Lumpur, Delhi, Chin State and Myanmar. I also used these wider networks to identify interviewees and research participants in Mizoram, and to find a research assistant and interpreter who was Mizo by birth but had worked with and was trusted by the Chin community in Mizoram.

My framing of this as a "refugee" situation also requires some explanation, as this is not how the Chin in Mizoram are defined in national or state law, or indeed at the local level. India has not ratified the 1951 Convention on the Status of Refugees and has no domestic refugee law. In the absence of a formal legal framework, India's responses to refugees are ad hoc and often nationality-specific. For Myanmar refugees, status determination is conducted by UNHCR in New Delhi and the Indian government has repeatedly refused status determination in Mizoram. The formal status of the Chin in Mizoram is therefore not as refugees but undocumented migrants. I analyse them as "refugees" notwithstanding, in recognition that refugee status is declaratory rather than constitutive (UNHCR 2011, H28). Most Chin in Mizoram migrated during military rule in Myanmar, when ethnic and religious persecution was widespread and when many, if not all, likely fulfilled the 1951 Convention criteria for refugee status. Since 2011, Myanmar has been engaged in political reform, including the election of a government led by the National League for Democracy. However, conditions in the country cannot yet be said to meet the fundamental and enduring change required to establish "ceased circumstances" under A1C(5) and (6) of the Refugee Convention (UNHCR 2003), and a continuing fear of

\footnotetext{
${ }^{3}$ Conversation recorded in field notes, $29^{\text {th }}$ August 2014.
} 
persecution persists for many. Describing the Chin in Mizoram as "refugees" is therefore consistent with principles of international refugee law if not with Indian policy. However, it is also appropriate to recognise that mixed migration movements have been common from Myanmar and that this defies blanket categorisation as either a "refugee" or "migrant" situation.

I was familiar with Indian refugee policy before beginning my fieldwork but was surprised to find that the language of "refugee" was also largely rejected at the local level, by Chin as well as Mizos. This would require another article to fully explore, but broadly speaking, among my Chin interviewees the label "refugee" was often associated with dependency and the pursuit of international assistance (particularly third-country resettlement) and rejection of this label was seen as a statement of independence and self-reliance. Mizo interviewees were more likely to refer to Indian policy in saying that people from Myanmar in Mizoram are not refugees. However, several Mizo interviewees also claimed that the term refugee was inappropriate because of a close ethnic relationship: "We are brothers and sisters and one people, one nation." These contrasting perspectives speak to a deeper ambiguity about the status of the Chin in Mizoram, the nature and implications of which are explored below.

\section{Introducing Mizoram and the Chin}

This article analyses relationships between Mizo and Chin as a series of processes of boundarycreation, boundary-policing and boundary-manipulation. In doing so, it draws on Migdal's (2004) concept of "virtual checkpoints" and "mental maps". Virtual checkpoints are "sites and practices that groups use to differentiate members from others and to enforce separation" (i.e. to differentiate insiders and outsiders), while mental maps are constituted by emotional and affective processes of defining allegiance. These are socially constructed processes which operate to define the parameters of group membership, and the framework captures day-to-day practices of boundary policing (virtual checkpoints) as well as an overall vision of belonging and difference (mental maps).

The "hasty scrawl of an imperial pen" drew Mizoram into India and the Chin Hills into Burma (Khilnani 2004: 31). Yet both groups recognise a common heritage, evidenced in similar

\footnotetext{
${ }^{4}$ Interview, Aizawl, $21^{\text {st }}$ July 2015
} 
physical appearance, languages and cultural practices. Mizo history describes migration from the Chin Hills, and many Mizo and Chin communities share an origin myth of emerging from a cave in Sinlung or Chhinglung (Sakhong 2009; cf Burling 2007). In recent political history Mizoram and Chin State have also shared experiences of colonisation, missionisation, conflict and insurgency. This has been a porous border for trade and people (Son and Singh 2016). From 1966 to 1985, Mizoram was steeped in a bitter insurgency and many sought safety across the border in Myanmar. After the Mizo Peace Accord was brokered the movement of people was overwhelmingly in the other direction. By the early 2000s, an estimated 100,000 Chin were living in Mizoram -10 per cent or more of the State population.

'Mizo' and 'Chin' are distinct identity categories which share some characteristics and overlapping memberships, including the groups known as Lai, Zomi, Lushai/Mizo and Lakher/Mara. Full exploration of the construction of Chin and Mizo identity is beyond the scope of this article but has been studied by other scholars (e.g. Pachuau 2014; Hluna 2013; Robin 2009; Sakhong 2003). Both are identities defined in distinction from their states of citizenship, India and Myanmar. Both are composite identities which seek to hold together a variety of constituent groups in intensely pluralistic societies. ${ }^{5}$ Both 'Mizo' and 'Chin' are also contested nomenclatures. Mizo identity is relatively more cohesive, with the identity and a common Mizo language recognised throughout the State. Three districts of Mizoram, the Lai, Mara and Chakma Autonomous Districts, are governed on the basis of an alternative ethnic identity. Here, and among some communities elsewhere in Mizoram, there are efforts to encourage ethnic languages, though Mizo remains the lingua franca. Chin identity is even more contested, lacking a common language and a generally accepted common nomenclature. I use the label 'Chin' to describe people originating from Chin State and those who define themselves as Chin from other regions in Myanmar (particularly Sagaing Division). This is consistent with the practice of the UNHCR in processing refugee claims from this region. However, many people categorised as Chin self-define differently, whether as a more local identity, an alternative umbrella identity or both.

Mizoram shares borders with Bangladesh, Myanmar and the Indian states of Tripura, Assam and Manipur. 'Outsider' populations include migrant workers from mainland India (known

\footnotetext{
${ }^{5}$ In Mizoram, the Indian government recognises 14 'scheduled tribes', while the 1982 Burma Citizenship Law recognised 'ethnic races', of which 53 are found in Chin State. These categories are politically and sociologically contested in both territories but continue to have important bureaucratic and administrative force.
} 
locally as vai), undocumented migrants from Bangladesh, and undocumented migrants and refugees from Myanmar (predominantly though not exclusively ethnic Chin). Attitudes to these populations are relevant to understanding the position of the Chin. Mainland Indians are not considered to belong to Mizoram though they share Indian citizenship, as Mizo attitudes to mainland Indians are shaped by a total absence of cultural affinity and by the memory of cruelties inflicted during the insurgency (Chakraborty 2009). Bangladeshi migrants are not considered to belong to Mizoram, despite their shared border, but are both resented and feared, with local views shaped by anxieties of "infiltration" (van Schendel 2005: 191-210). In 2018, construction will be complete on a 4000km border fence along the Mizoram-Bangladesh border, built by the central Indian government but supported by Mizo public opinion (McDuie$\mathrm{Ra}$ 2014). Even some indigenous communities are excluded from the popularly defined Mizo identity, notably Chakma and Bru (Patniak 2008: 81-84), who have experienced rejection and expulsion into Bangladesh (Chakma) and Tripura (Bru). Tens of thousands of Bru have been living in refugee camps in Tripura since they were forced out of Mizoram in 1997. Attempted repatriations failed in 2010 and 2017, as the Bru refused to return without guarantees of their safety. Chakma are a sizable ethnic group in Mizoram, recognised as a Scheduled Tribe by the Indian government and with a Chakma Autonomous District Council in Mizoram since 1972. Nevertheless, there is strong opposition to their presence in Mizoram from the wider Mizo population.

Thus, while the territorial border shapes perceptions of belonging it is far from determinative. Indeed, among the various 'outsiders' mentioned above, only the Chin have a possibility of belonging. Proposals to fence the Myanmar border were rejected by the State government and Myanmar border residents have freedom to travel within $16 \mathrm{~km}$ of the border (previously $40 \mathrm{~km})$. The Chin are not Indian citizens but they are often able to acquire documentation associated with citizenship, such as a ration card, an electoral identity card or a passport. Securing such documentation is widespread in India and beyond, as undocumented immigrant populations seek to avoid the risks and dangers of living sans-papiers. As Sadiq (2009) recognises, this practice may best be understood as a specific type of citizenship, a 'documentary citizenship' that confers important bureaucratic benefits without necessarily implying belonging or acceptance. However, acquiring such documents typically requires assistance from within the host population, and the extent to which Chin refugees gain this cooperation from Mizo community leaders and others is perhaps where their privileged stake to belonging is most apparent. 
Other practices of belonging are found in shared spaces and places (such as schools, housing and church) and in marriage and other relationships. Christianity is an important social force in Mizo and Chin communities, and social integration for Chin can be advanced by attending Mizo church and participating in the religious life of a locality. Chin children can also attend Mizo schools (in contrast to Malaysia, where refugees are denied access to state education). Relationships and marriages between Chin and Mizo are relatively common, though I found that any problems were attributed to the "mixed" nature of the marriage. For example, several Chin women that I interviewed claimed that domestic violence was more common in relationships between Chin women and Mizo men, while Mizo interviewees told me that Chin women were liable to steal from or abandon a Mizo husband. Such statements imply deepseated suspicion and prejudice between the communities; yet the frequency of relationships and marriage also demonstrates a proximity between Mizo and Chin which is not apparent between Mizo and Bangladeshi migrants or 'mainland' Indians.

Indeed, many Mizos feel they have extended generosity to the Chin which has been insufficiently recognised, and note that some Chin in Mizoram hold professional jobs and are fully integrated within Mizo neighbourhoods, churches etc. This is true for some - and it should certainly be recognised that Mizoram is the only destination for Chin refugees that affords any opportunity to succeed professionally - but it is not representative of the majority. A typical lifestyle for Chin in Mizoram is precarious employment (subsistence trade, domestic workers, weavers, agricultural or stone-quarrying), living in a run-down area and socialising primarily with other Chin. Chin in Mizoram are also liable to encounter a variety of forms of discrimination, ranging from name-calling and insults to labour exploitation and, on multiple occasions over the past twenty years, burning down houses and push-backs to Myanmar (Hre Mang 2000; Levesque and Rahman 2008; Human Rights Watch 2009; Basavapatna 2012). In these very significant ways, the dominant 'mental map' in Mizoram has followed the State's territorial borders to define the Chin as aliens and foreigners.

\section{Boundary Making: virtual checkpoints and the Chin as Other}

"People will tell you that there is no problem but actually there is a problem. Burmese are looked down on and viewed as inferior. They are associated with negative things, they say that 'nothing good comes from the east but the sun'. If someone is a little ugly 
they will be described as having a 'Burmese face'. Crime and social problems are attributed to Burmese presence and influence."

Herzfeld (2005) notes that "nationalism is directly predicated on resemblance [...] the pivotal idea is that all citizens are, in some unarguable sense, alike". A corollary to this can be that when designated 'outsiders' closely resemble the insider community, great efforts are made to minimise that resemblance and avoid a claim to belonging, typically by identifying and emphasising markers of difference. These are Migdal's 'virtual checkpoints', and the comment above - from a Mizo woman - indicates some of the most common checkpoints used to distinguish Chin from Mizo, including nationality, appearance and perceived criminality. The most common Mizo term used to describe Chin is "Burma-mi". The literal meaning is "from Burma" or "Burma-people" but the phrase is laden with other assumptions (of inferiority, poverty, stupidity) and is perceived and often intended as an insult. The label of Burma-mi is ironic for the Chin, the vast majority of whom reject an identity as "Burmese". Its prevalence in Mizoram underscores the continued importance of the border and the boundary between citizen and foreigner in asserting a sense of difference between the two communities.

Virtual checkpoints are also found in names, language, accent and pronunciation, dress, hair and physical appearance, i.e. the "tells" used to distinguish a genuine insider from a similar outsider. The most significant virtual checkpoint - recognised as such by both Mizos and Chins - centres on laws and norms. This is a familiar story, established in a large literature on scapegoating and the production of migrant illegality (Dauvergne 2008; de Genova 2004; Menjivar and Kanstroom 2014). Rumours and labelling are central processes in defining the 'other', and frequently centre on alleged deviance and criminality to establish an essential incompatibility with the host community (Kushner 2006).

Laws of particular concern in Mizoram relate to the sale of alcohol and supply of drugs. Between 1995 and 2015, alcohol was entirely prohibited in Mizoram. Prohibition was instigated by the Presbyterian Church and though it was legally lifted by the State Government in 2015 the Church continues to oppose any use of alcohol. In Chin State, there is no such prohibition. Despite Prohibition, alcohol is readily available in Aizawl. Several districts in the city are notorious for small-scale alcohol distilleries and the Chin are widely blamed as the main operators of these (see further Son and Singh 2016: 362). Drug addiction has been a debilitating social problem in Mizoram for more than twenty years, with the source of the 
addiction moving from heroin to opium to amphetamines and currently an emerging problem with methamphetamine. The strongest opposition to Chin presence in Mizoram is based on claims that they are responsible for alcohol production and drug-trafficking. In other respects too, the Chin in Mizoram are associated with rumours of crime. These include tales of domestic workers stealing from home owners, and of the rape of Mizo women by Chin men. Pachuau (2014: 193) comments that during her research fieldwork, "All crime in Mizoram, from petty theft to gruesome murders, was blamed on the Burmese", while Basvapatna (2012: 64) remarks on "clearly selective" targeting of Chins in policing. My interviews were consistent with this, and with the presence of deep-seated distrust of the Chin:

"We say, nothing good comes from the East but the sun."

"Every single time there is drug haul and arrests it always will be Myanmarese. [...] They give themselves a Mizo name but the place they come from is always Tahan or somewhere else in Burma. The public perception of these people is, they bring drugs to our land, they kill our children. This is why sometimes the host community may be reserved or suspicious. [...] The degree of crime and kind of crime in the past was limited. For past decades after influx they bring all kinds of social crimes. ",

"People here accepted the Burmese, gave them jobs, took them into their homes and were repaid with theft and deceit. Their maids who they trusted with their home and children sold their goods and ran away. The Burmese brought drugs into the community and killed their children." 8

\section{Boundary Policing: enforcing the checkpoints}

It has been argued above that the local reception of Chin in Mizoram is shaped by perceptions of identity, the boundaries of which are marked by virtual checkpoints which distinguish the other (Chin) from the insider (Mizo). Virtual checkpoints are cognitive markers but they produce real consequences and are often policed with as much zeal and determination as a physical border checkpoint, albeit with different methods. Virtual checkpoints are policed in

\footnotetext{
${ }^{6}$ Interview, Aizawl, 25 $5^{\text {th }}$ August 2014 (this phrase was repeated in several other interviews and conversations).

${ }^{7}$ Interview, Mizoram University, $28^{\text {th }}$ August 2014.

${ }^{8}$ Field notes, $24^{\text {th }}$ August 2014
} 
part through gossip, prejudice and the groupthink of 'popular opinion'. They are also shaped by institutions and organisations. A local joke says that there are three governments in Mizoram: the State parliament, the Presbyterian Church and the Young Mizo Association (YMA). Of the three, the strongest influence on public opinion may well be the YMA, which has a membership of 400,000 people (almost half the state population, and the majority of adults in the state) and nearly 800 branches state-wide. This gives it influence and weight far beyond a conventional community-based organisation. YMA is not the only community-based organisation to play such a role (other leading organisations include the Mizoram Upa Pawl/Senior Citizens Association and the Mizo Hmeichhe Insuihkhawm Pawl/ Mizo Women's Organisation) but it is the most influential.

Many Mizos view these organisations, and YMA in particular, as an essential part of the Mizo social fabric constituted by and constitutive of the trait of tlawmngaihna, an ethos of selfsacrifice, consideration and care for others. YMA is valued for its work in organising funerals, caring for the elderly and rescuing people injured in landslides or swept away by rivers. It is an immensely successful community organisation in its practical achievements and a powerful example of civil society's role in the production of identity. However, communitarianism can also have a dark side, fostering parochialism, insularity and the exclusion of outsiders. The YMA's role as the primary guardian of Mizo culture has given it a central role in policing the boundaries of 'Mizo-ness' - and, therefore, in policing the virtual checkpoints between Mizo and Chin.

YMA has influenced the lives of Chin in Mizoram in three key areas. First, as the pre-eminent community organisation in Mizoram, YMA local branches opposed any parallel organisations emerging, which extended to disapproval of attempts by the Chin to develop their own organisations. This resistance to parallel organisations was shared by the Presbyterian Church in Mizoram, which objected to the establishment of 'Chin' churches. This forced Chin organisation into a shadowy, illegitimate space and inhibited the development of strong community networks. A partial exception existed for women's groups, of which several were formed in the early 2000s though few remain in operation today (Norwood and Zahau 2011).

A second way in which YMA has monitored the "virtual checkpoints" between Chin and Mizo has been through local policing. YMA's activities include an informal policing function and local YMA branches will intervene to address, for example, youth misbehaviour or fighting. 
This function has been most active in relation to alcohol and drugs. YMA typically adopts an annual theme to define a priority area. From 2004 until 2009, the theme was 'Fight Against Intoxicants', and YMA established two policing units: Supply Reduction Service (SRS) and Demand Reduction Service (DRS). The policing approach taken by these units relied largely on humiliation and intimidation, using beating and public shaming, though this has been revised recently to incorporate community service and mediation outcomes. While technically a non-discriminatory policing function, YMA members and Chin interviewees agreed that the Chin were policed more aggressively than Mizo suspects.

Finally, and most significantly, YMA has on occasion actively organised forced removal of Chin from Mizoram (Basavapatna 2012; Human Rights Watch 2009). Chin migration to Mizoram began in earnest in the mid-1980s and increased during the early 2000s with a combination of worsening political conditions in Myanmar and famine in Chin State. From 1999 to 2004, YMA's annual theme reflected anxiety at the influx: 'Safeguarding Nation and Land' (1999-2002) and 'Self-Reliance' (2003-2004). These themes were distilled into antiforeigner campaigns and forced returns to Myanmar, which occurred in 2003, 2008 and 2009, 2010 and 2013. The 2003 campaign was particularly intensive. It occurred after a young girl was raped in Aizawl and a Chin man was accused of the crime. In the aftermath, more than 10,000 Chin were returned to Myanmar. YMA members were at the forefront of these antiforeigner campaigns, which were perceived as separating the "good" Chin from the "bad" (Basavapatna 2012: 65). A Village Council President interviewed by Pachuau (2014: 194-5) commented, "Just as the seed and husk separate on its own while winnowing, similarly, at the time of the call for expulsion, all those who know they had to leave, left."

William Singh has analysed the use of "quit Mizoram" notices as a key tactic in defining and imposing a Mizo identity that he argues is intrinsically xenophobic - and indeed, the stance that "Mizoram is for the Mizos" has been applied to Indian nationals, Bru and Chakma as well as the Chin (Singh 2014; Son and Singh 2016). For the Chin, forced returns to Myanmar have been the most extreme manifestation of anti-foreigner mobilisation but they must be understood within a wider climate of prejudice and discrimination (Levesque and Rahman 2008; Human Rights Watch 2009). Some of this remains endemic, a casual discrimination that is largely unnoticed by Mizo society but is apparent in jokes, derogatory remarks and a general belief of Mizo superiority and Chin inferiority. This behaviour is not as extreme as deportation 
but it is painful nevertheless. One of my interviewees, a young man in his twenties, described the internal conflict of being born and raised in Mizoram as a Chin:

"My mother and father are Chin and I am Chin [... I I was raised here and in my experience I struggled often. I was called "Chin" "Chin boy" often. But I was raised in Mizoram, I think of myself as a Mizo boy. The way I speak, act, feel, see, it is like a Mizo. I think I am a Mizo guy. Then I realised that Chin is in my blood so why the hell call myself a Mizo boy?"

\section{Boundary Manipulation: redrawing the boundaries}

So far this article has told a familiar story, of opposition to a refugee influx manifested in the creation and policing of boundaries between those who belong in Mizoram and those who do not. Resentment of the Chin appears to be driven by a variety of 'fears of the other', including a fear of domination by an outsider population that is shared by other north-eastern territories and is particularly acute in relation to Bangladeshi migrants, Indian mainland workers and Muslim migrants (Son and Singh 2016; Singh 2014; Basavapatna 2012; Human Rights Watch 2009; Levesque and Rahman 2008). Other fears include the risk of fostering disunity in Mizoram and weakening the society through moral and cultural deterioration or by 'catching' Myanmar's political and economic instability.

However, there is a counterpoint to this refrain which draws the boundaries of identity and territorial belonging rather differently and recognises the Chin and Mizo as related ethnic communities existing in a shared ancestral territory. This can be seen as part of a wider inquiry into the history of Mizos which is challenging colonial-era narratives of Mizo identity and origin (Pachuau 2014; Piang 2013; Dena 2013; Zama 2006; Hluna 2013; Thantungnung 2015). In Chin-Mizo relations, this has often been tied to identity discourses and the assertion of a pan-ethnic identity which emphasises the shared cultural origins of the two communities. Panethnic identities have been asserted under various labels (such as Zo, Mizo, Lai and Kuki), each representing different parameters of kinship. The most influential pan-identity movement in Mizoram is Zo, which incorporates those groups currently categorised as Chin, Mizo and Kuki and therefore includes residents of Mizoram, Chin State and Sagaing Division in Myanmar;

\footnotetext{
${ }^{9}$ Interview with members of a Chin church, Aizawl, 25 ${ }^{\text {th }}$ July 2015.
} 
Assam, Manipur, Nagaland and Tripura in India; and the Chittagong Hill Tracts in Bangladesh. Zo is one of several similar identity movements in the Northeast India, which have variously been described as "cosmopolitan identities", "micro-nationalisms" and "adjacent identities" (D. Zou 2010; S. Zou 2012; McDuie-Ra 2015). These identity movements reject the sovereign and territorial nationalism of India and Myanmar in favour of an identity-based ethnonationalism. In effect, they are postcolonial identity movements linked to conceptions of precolonial ethnic unity. Some of this work arguably presents an idealised harmonious and egalitarian past, but the central idea of a pan-ethnic identity has had considerable impact.

Zo identity is not a recent invention (Vumson 1986; Son-Doerschel 2013). Nevertheless, its influence as a modern identity movement in Mizoram might be dated to 1991 and the decision of the Zo Reunification Organisation (ZORO) to establish a "non-political, ethnic-based organisation" for all Zo, "so that political boundary would not be a hindrance" (Thangmawia 2013: 3). ZORO sought to engage international frameworks of indigenous rights, eventually securing recognition by the United Nations and participation in UN mechanisms as an indigenous population of Zo (see e.g. ZORO 2015). ZORO initially had little mainstream support but has gained greater acceptance in its own right and catalysed other organisations to work under a similar premise, including Zo Indigenous Forum and Zofa Global Network. Some of these organisations have also undertaken international advocacy, but their primary focus has been more local, with particular emphasis on cross-border gatherings. For example, ZoFest is organised by Mizoram's MZP student union as a gathering of Zo from Mizoram, Manipur, Tripura, Chittagong Hill Tracts and Chin State. ZoFest was first held in 2002 in Manipur and regularly thereafter in Mizoram and other locations - but never Myanmar. It was significant, therefore, that Myanmar's second student union (MSU) organised a 'Chhinlung Cultural Festival' in Chin State in 2014.

These events and many others have emphasised themes of brotherhood, ethnic unity and kinship, of Mizo and Chin as Zofate (children of Zo) and Zo hnahthlak (Zo brothers). This suggests a changing understanding of boundaries and belonging, which has been instigated by residents of Mizoram (both Mizo and Chin) and by Chin diaspora. Over the past twenty years, many Chin refugees in New Delhi and Malaysia have been resettled to 'third countries', typically the United States and Australia. This has established the Chin as a transnational community with considerable political status, and a diasporic elite has sought to raise awareness about conditions for the Chin through human rights monitoring and lobbying (see 
e.g. CHRO 2012; Seeking Refuge 2011) and more diffuse strategies of political engagement. Mizo public opinion is profoundly shaped by internal elites, including singers and musicians, journalists and media commentators. The Chin diaspora has made calculated appeals to these sectors by, for example, inviting Mizo singers to perform at concerts for resettled Chin communities in the USA. These concerts offer entertainment by hugely popular musicians such as Mami Varte (who performed in a US tour organised by the Chin Youth Organisation in 2013). However, they have also served a public relations agenda, to counter Mizo perceptions of the Chin as deviant and destitute.

Interest in Myanmar has also been fostered by Mizo media outlets which produced news stories and TV documentaries discussing Myanmar's art and culture, natural resources, and wealthy cities of Yangon and Mandalay. This rich history of power and status has been a revelation to many Mizos, more familiar with Myanmar as a failed state than the 'rice basket of Asia'. An influential documentary about Chin State emphasised similarities between Chin and Mizo, such as shared cultures of hospitality and generosity. This was an explicit attempt to build better relations, as its producer explained:

"My role as a Mizo is to introduce Chin State to the people here in Mizoram. People in Aizawl totally don't know about their neighbours [...] we think of them as primitive [...] When the documentary was broadcast the impact was beyond my imagination." 10

One result has been to make Myanmar a country of interest for Mizos, even a tourist destination:

"For past decades, Mizos have always looked west. Now they are starting to be interested in what is east." 11

It is impossible to quantify the impact of these attempts to shape perceptions of the Chin. However, many of my interviewees felt that conditions had improved in recent years and cited less name-calling, fairer treatment by employers and no recent push-backs across the border. ${ }^{12}$

\footnotetext{
${ }^{10}$ Interview, Aizawl, $28^{\text {th }}$ July 2015.

${ }^{11}$ Interview, Aizawl, $28^{\text {th }}$ July 2015.

${ }^{12}$ E.g. interview with Chin teacher, Aizawl $15^{\text {th }}$ July 2015; Chin tea seller, Aizawl, 22 ${ }^{\text {nd }}$ July 2015; Chin woman vegetable seller Lawngtlai, $5^{\text {th }}$ August 2015.
} 
They attributed these changes in part to better understanding of Myanmar and the Chin. An illustration of this apparent change of heart came during my fieldwork in 2015, when monsoon rains caused landslides in Chin State which destroyed hundreds of houses, left thousands of people homeless and blocked road access. Mizoram embarked on a massive fund-raising drive, from the state's Chief Minister (who requested the Indian Government to provide aid and proposed Mizoram as a base for helicopter aid deliveries) to student unions (who asked their members to donate one day's lunch money). The Young Mizo Association sent trucks loaded with rice to Chin State. Churches prayed, fasted and collected hundreds of thousands of rupees in donations. Mizo singers and celebrities organised a TV charity concert and a three-day event at Aizawl's central shopping mall. Many organising the relief events had never previously supported the Chin - and in some cases, had been the key ringleaders encouraging their rejection. A language of co-ethnicity and kinship was prominent during these fundraising efforts, which consistently described the beneficiaries as "our brothers and sisters in Burma", suggesting an important labelling shift from foreigner (Burma-mi) to kin (Zo hnahthlak and Zofate). This in turn suggested that a message that was unpalatable to many Mizos even twenty years ago - the essential similarity of Mizo and Chin - had been embraced not merely by a fringe of society but by mainstream opinion formers such as the Presbyterian Church and the YMA.

However, the long-term implications of this pan-ethnic identity movement are more complex. By emphasising kinship between groups currently resident in several territories of India and Myanmar, Zo identity implies redefined geographical borders. There is limited support in Mizoram or Chin State for a secessionist movement to establish a 'Zoram', but the symbolic recognition of such a territory is at the heart of events such as ZoFest. Some Mizos fear that this is a political agenda that in the worst case scenario may lead to political violence and jeopardise Mizoram's hard-won stability. Others are concerned with distribution of resources and the risk of dilution of Mizo identity. Still others see it as short-sighted political opportunism from groups that seek to benefit from Chin political support:

"Students, YMA, political parties: when it suits political purposes they are our brothers; when it doesn't, they are outsiders [...] People are illegal but political parties 
want their votes. They make promises. These people are valuable vote-banks. All of the parties do that.",13

Among Chin in Mizoram, a converse fear prevails: that 'Zo' identity is indistinguishable from Mizo identity, and therefore that greater ethnic belonging with Mizos will diminish or eradicate other identities. Zo identity scholars describe it as universally accepted by Chin (e.g. Son 2013, Son 2014) but many of my Chin interviewees in Mizoram and elsewhere disagreed. They were concerned that Zo identity was assimilationist and had become the most acceptable pan-ethnic identity movement in Mizoram precisely because it accepted the Chin as an extension of Mizo identity rather than as a threat to that identity:

"Mizos want to assimilate other groups. Even ZORO, their idea of integration is assimilation: that Zo - which is Mizo - will be the term and that Mizo will be the common language." 14

"Chin people cannot accept to be called Mizo, and the Mizo people will never accept to be called Chin." 15

My Chin interviewees did not necessarily consider Zo identity as a desirable ideology but did think that it had influenced Mizo perceptions of Chin. This suggests that appropriately targeted interventions can help to influence public opinion, which is a hopeful finding for refugee reception generally. However, even those who believed that prejudice against the Chin had reduced were not convinced that this represented enduring change:

"Compared to 2000 and 2003 [times of violent removal of Chin from Mizoram], the situation is totally different now. Mizos have opened their eyes, they care about human rights and about international perception",16

"We will see. The next time that there is a serious crime, a rape or a murder, it will all be forgotten." 17

\footnotetext{
${ }^{13}$ Interview, Mizoram University, $28^{\text {th }}$ August 2014.

${ }^{14}$ Interview, Lawngtlai $3^{\text {rd }}$ August 2015.

15 Interview, Aizawl, $18^{\text {th }}$ August 2015.

${ }^{16}$ Interview, Aizawl, 15 ${ }^{\text {th }}$ July 2015.

${ }^{17}$ Interview, Aizawl, 24 ${ }^{\text {th }}$ July 2015.
} 
"Mizo people understand a bit more about Burma so the situation is a bit better but that could change again. They still consider us bad people." 18

Support for the view that tolerance of the Chin was conditional and provisional rather than principled and lasting came in 2016 (when YMA demanded the removal of Chin from Mual Khang village who were alleged to have been brewing alcohol) and again in 2017 when violence in Myanmar's Rakhine State sent hundreds of Chin to seek safety in Mizoram. Arrivals in May 2017 were immediately returned "to avert a major refugee crisis that could have lingered in Mizoram”. Months later, renewed fighting forced a further 1600 Chin to flee to Mizoram's Lai Autonomous District. Initial reports quoted the district police chief's statement that "we would not push back the refugees due to humanitarian grounds. The people who crossed over to Mizoram were mostly Buddhists and Christians and they speak the same tribal language as the locals" (New Indian Express 2017). Soon after, repatriation plans were announced. When this was attempted in January 2018, more than 1400 refugees refused to return.

Similarly, even as the virtual checkpoints have been less rigorously policed for (some) Chin in Mizoram, they have escalated for other perceived 'outsiders'. Proposals to repatriate Bru refugees forced from Mizoram in 1997 are actively resisted, even (perhaps especially) by organisations and individuals who have promoted Mizo-Chin unity. Anti-Chakma activism has also escalated, even though Chakmas have a legally recognised autonomous district in Mizoram. In 2017, a political proposal sought to eject all Chakma born in Mizoram after 1950, and leading Mizo community organisations organised a large protest in New Delhi against illegal immigration in Mizoram, explicitly targeting Chakma (Newmai News Network 2017, Chakma Social Forum 2017). Mizo community organisations have also campaigned to intensify policing along the Mizoram-Bangladesh border (Khojol 2017). The Chin have not been targeted in this latest round of anti-foreigner activism. During my fieldwork, a Zo activist said that he had initially worked under a human rights rubric but no longer defined his work this way "because human rights requires us to provide the same services to everyone and I want to prioritise our community, our people." ${ }^{19} \mathrm{He}$ included the Chin within this ambit but

\footnotetext{
${ }^{18}$ Interview, Aizawl, $25^{\text {th }}$ July 2015.

${ }^{19}$ Interview, Aizawl $21^{\text {st }}$ July 2015.
} 
explicitly excluded Bru and Chakma: "all that we have in common, the only thing that we have in common, is that we are human beings". He did not consider this shared humanity sufficient justification for Bru and Chakma to live in Mizoram.

This suggests an important conclusion regarding overlapping identities or intersectionality. Defining "belonging" and an entitlement to belong is a process that ascribes value to different identities, and that value can shift over time (e.g. Madsen and Van Naerssen 2003; Fincham 2012). However, identities are multiple and overlapping. Refugee studies as a disciplinary field has prioritised refugee identity as an analytic category. However, refugees are also individuals who exist within multiple communities of belonging, potentially related to (e.g.) national, ethnic, racial, religious, gender and sexual identities. The experience of Chin and others in Mizoram suggests that it is these identities that are most influential in defining the boundaries between insiders/outsiders - and therefore where there is greatest space for redrawing those boundaries to encourage or enhance belonging.

Where Chin have been accepted as having a claim to 'belong' in Mizoram, it has been on the basis of a shared ethnic identity, shared religion and similar culture and language. These commonalities have been permitted to prevail over the difference of nationality. In contrast, the Bru and Chakma are not accepted as Mizo: differences of faith and culture outweigh the connections of shared territory, nationality and citizenship. A further example is provided by Raheja (this issue) in relation to Pakistani Hindus in northern India, where shared religion cannot redeem in local eyes the fatal flaw of Pakistani nationality. These examples suggest the importance for refugee studies in paying greater attention to intersectional identities, to better understand the weight and value attributed to different identities - and therefore to understand, predict (and perhaps even alter) perceptions of refugees by host communities.

\section{Conclusion}

This article has argued that the local reception of Chin refugees in Mizoram is shaped by perceptions of belonging, which can be understood in relation to a "mental map" of affiliations and "virtual checkpoints" of difference. It has noted that while Mizo and Chin identity discourses reject identification as Indian or Burmese, negative perceptions of the Chin in Mizoram have been reinforced by virtual checkpoints which essentially reconstitute the Indian border. Those virtual checkpoints facilitate processes of boundary policing which have 
manifested in discrimination, prejudice and forced removals from Mizoram. However there has also been an alternate discourse of kinship, co-ethnicity and brotherhood, often expressed through Zo identity. These discourses of othering and brotherhood coexist but have taken the ascendance at different points. The important question therefore becomes when and where each has been deployed, and what that might tell us about the factors shaping 'boundaries and belonging' for Chin in Mizoram.

Mizo opposition to the Chin has been strongest when identity is defined in terms of national borders: i.e. Mizos are from Mizoram and Chin are Burmese (Burma-mi). In contrast, acceptance of Chin has been strongest when identity is defined in accordance with ethnicity: i.e. when Mizo and Chin are understood as co-ethnics. Empathy for Chin refugees has been influenced by deliberate efforts from Mizo and Chin alike to reshape the boundaries of identity and establish a more inclusive approach to ethnicity. This is a reminder that cartographic lines do not dictate mental maps of belonging, hospitality and acceptance. Similarly, analyses of integration and immigration typically place national laws and policies at the centre, but these are not the most important influences in every refugee situation - and certainly not in Mizoram, where reception of the Chin and others has been dictated by local community organisations rather than Indian Government or Mizoram State policies, and where claims for entitlement to protection have been made not on the basis of their status as refugees but as members of a common ethnic and cultural heritage. This underscores the importance of contextualising refugee reception in terms of refugees' multiple identities and in terms of the wide range of political, economic, social and cultural factors that influence the construction of boundaries and belonging. 


\section{REFERENCES}

AGER, A AND STRANG, A. (2010) 'Refugee Integration: Emerging Trends and Remaining Agendas'. Journal of Refugee Studies 23(4): 589-60.

BARTH, F. ed. (1969) Ethnic Groups and Boundaries. London: Allen \& Unwin.

BARUAH, S. (2003) 'Citizens and Denizens: Ethnicity, Homelands and the Crisis of Displacement in Northeast India' Journal of Refugee Studies 16(1):44-66.

BASAVAPATNA, S. (2012) 'Chins in Mizoram: The Case of Borders Making Brothers Illegal'. Journal of Borderlands Studies 27(1):61-72.

BRUN, C.; FABOS, A.H. and EL-ABED, O. (2017) 'Displaced citizens and abject living: The categorical discomfort with subjects out of place', Norwegian Journal of Geography 71(4):220-232.

BURLING, R. (2007) 'Language, Ethnicity and Migration in North-Eastern India'. South Asia: Journal of South Asian Studies.

CASTLES, S., DAVIDSON, A. (2000) Citizenship and Migration: Globalization and the Politics of Belonging, New York: Routledge.

CHAKMA SOCIAL FORUM (2017), 'Chakma leaders term the Mizo Zirlai Pawl's Delhi protest as contempt of the Supreme Court and ask them to stop vilification of Chakmas as foreigners' 28 October 2017.

CHIN HUMAN RIGHTS ORGANISATION (2012) Threats to Our Existence: Persecution of Ethnic Chin Christians in Burma. Available at < http://www.chro.ca/index.php/publications/73-special-reports/411-threats-to-our-existence> (accessed 30 June 2017).

DAS, B. (2011) 'Presence of Illegal Immigrants in Contemporary Assam: Analysing the Political History of the "Problem"” Eastern Quarterly 7(III):104-113. 
DAUVERGNE, C. (2008) Making People Illegal: What globalization means for migration and law. Cambridge: Cambridge University Press.

DELANTY, G., WODAK, R. and JONES, P. eds. (2008) Identity, Belonging and Migration Liverpool: Liverpool University Press.

DENA, L. (2013) Selected Mizo Folktales Rereading in the Context of Modernization and Globalization. Khatla: Lengchhawn Press.

DE GENOVA, N. (2004) 'The Legal Production of Mexican/Migrant Illegality'. Latino Studies 2(2):160-185

HAOKIP, T. (2016) 'Spurn thy Neighbour: the Politics of Indigeneity in Manipur' Studies in Indian Politics 4(2):178-190.

HERZFELD, M. (2005) Cultural Intimacy, $2^{\text {nd }}$ ed. Abingdon: Routledge.

HLUNA, J.V. (2013) History and Ethnic Identity Formation in North-East India. New Delhi: Concept Publishing.

HOVIL, L. (2016) Refugees, Conflict and the Search for Belonging, Basingstoke: Palgrave Macmillan.

HRE MANG (2000) Report on the Chin Refugees in Mizoram State of India. Available at < http://www.hremang.com/vangtlang-nun/chin-refugee-report-2000>(accessed 30 June 2017).

HUMAN RIGHTS WATCH (2009) “We are like forgotten people”. The Chin people of Burma: Unsafe in Burma, Unprotected in India. Available at < https://www.hrw.org/report/2009/01/27/we-are-forgotten-people/chin-people-burma-unsafeburma-unprotected-india> (accessed 30 June 2017).

KHILNANI, S. (2004) The Idea of India. Delhi: Penguin Press.

KHOJOL, H. L. (2017) 'Mizoram looking at ways to stop immigrants from Bangladesh', Zoram Observer 22 December 2017. 
KUSHNER, T. (2006) 'An alien problem? Criminality and immigration' Criminal Justice Matters 65(1): 14-15.

LEVESQUE, J. and RAHMAN, M.Z. (2008) Tension in the Rolling Hills: Burmese Population and Border Trade in Mizoram, New Delhi: IPCS Research Paper.

MCDUIE-RA, D. (2014) 'The India-Bangladesh Border Fence: narratives and political possibilities'. Journal of Borderlands Studies 29(1): 81-94.

MCDUIE-RA, D. (2016) 'Adjacent identities in Northeast India', Asian Ethnicity, 17(3): 400413.

MENJIVAR, C. and KANSTROOM, D. (2014) Constructing Immigrant 'Illegality': Critiques, Experiences and Responses. Cambridge: Cambridge University Press.

MIGDAL, J. S. (2004), 'Mental Maps and Virtual Checkpoints', in J. S. Migdal, ed., Boundaries and Belonging: Status and Societies in the Struggle to Shape Identities and Local Practices. Cambridge: Cambridge University Press, pp1-23.

NEW INDIAN EXPRESS (2017) 'Mizoram provide shelter to 1300 Myanmar tribals fleeing clashes’ 27 November 2017.

NEWMAI NEWS NETWORK (2017) 'ZNP suggests expulsion of Chakmas who entered Mizoram after 1950' Available at <http://morungexpress.com/znp-suggests-expulsionchakmas-entered-mizoram-1950/> (Accessed 10 January 2018).

NORWOOD, G. and ZAHAU, C. (2011) 'Fostering a Grassroots Women's Movement through Feminist Leadership on the Burma-India Border'. Women \& Therapy 34(3): 223-241.

PACHUAU, J. (2014) Being Mizo. Oxford: Oxford University Press.

PATNIAK, J.K. (2008) 'The State and Civil Society' in Mizoram: The Post-Accord Syndrome, in Mizoram, Dimensions and Perspectives: Society, Economy and Polity. New Delhi: Concept Publishing. 74-91. 
PIANG, L.L.K. (2013) 'Ethnic mobilisation for decolonisation: colonial legacy (the case of the Zo people in Northeast India)' Asian Ethnicity 14(3):342-363.

ROBIN, K. (2009) Chin History, Culture Identity. Delhi: Dominant Publishers.

SADIQ, K. (2009) Paper Citizens: How Illegal Immigrants Acquire Citizenship in Developing Countries. Oxford: Oxford University Press.

SAKHONG. L.H. (2009) 'The Origins of the Chin', in K. Robin, ed. Chin: History, Culture, Identity. Delhi: Dominant Publishers.

SAKHONG, L.H. (2003) In Search of Chin Identity. Copenhagen: NIAS Press.

SINGH, N. W. (2014) 'Quit Mizoram Notices: Fear of the Other’ Economic \& Political Weekly 49: 25 .

SON, B. and SINGH, N. W. (2016) 'The Chin State-Mizoram Border: Institutionalised Xenophobia for State Control' in S. Oh, ed. Myanmar's Mountain and Maritime Borderscapes: Local Practices, Boundary-Making and Figured Worlds. Singapore: ISEAS.

SON-DOERSCHEL, B. (2013) The making of the Zo: The Chin of Burma and the Lushai and Kuki of India through colonial and local narratives 1826-1913 and 1947-1988. PhD Thesis. SOAS, University of London.

THANGMAWIA (2013) Zo Conference 2013 Aizawl: Synod Press.

THANGTUNGNUNG, H. (2015) Ethnic History and Identity of the Zo Tribes in North East India Journal of North East India Studies 5(1), 39-50.

UNHCR (2003) Guidelines on International Protection: Cessation of Refugee Status Available at <http://www.unhcr.org/uk/publications/legal/3e637a202/guidelines-internationalprotection-3-cessation-refugee-status-under-article.html> (Accessed 30 June 2017) 
UNHCR (2011), Handbook on Procedures and Criteria for Determining Refugee Status. Available at < http://www.unhcr.org/uk/publications/legal/3d58e13b4/handbook-procedurescriteria-determining-refugee-status-under-1951-convention.html> (Accessed 30 June 2017).

VAN HOUTUM, H. AND VAN NAERSSEN, T. (2002) 'Bordering, Ordering and Othering' Tijdschrift voor Economische en Sociale Geografie 93(2): 125-136.

VAN SCHENDEL, W. (2005) The Bengal Borderland: Beyond State and Nation in South Asia. London: Anthem Press.

VUMSON, (1986), Zo History, Published by the author. Available at < http://www.burmalibrary.org/docs12/Zo_History-Vumson.pdf> (Accessed 30 June 2017).

YUVAL-DAVIS (2006) 'Belonging and the politics of belonging' Patterns of Prejudice 40(3): 197-204.

ZAMA, M. C. (2006) 'Globalization and the Mizo Story’ Indian Folklife 22: 10-11.

ZORO (2015) Statement at the $14^{\text {th }}$ Session of the UN Permanent Forum on Indigenous Issues. Available at <http://papersmart.unmeetings.org/media2/4657730/zoro.pdf> (Accessed 30 June 2017).

ZOU, D. V. (2010) 'A Historical Study of 'Zo' Struggle'. Economic and Political Weekly, 45(14): 56-63.

ZOU, S.T. (2012) 'Emergent Micro-National Communities: The Logic of Kuki-Chin Armed Struggle in Manipur'. Strategic Analysis 36(2): 315-327. 